\title{
Information, processing and visualization of historical traces and architectural and urban fragments in Maracaibo: A theoretical-methodological approach from information technologies
}

\author{
Jane Espina Bermúdez \\ Universidad del Zulia | Venezuela | jjespina@yahoo.com
}

\begin{abstract}
The work presents a theoretical-methodological proposal for the registration, processing and visualization of historical traces and architectural and urban fragments of the SpanishAmerican models and the oil camp established in Maracaibo, based on ongoing research. The methodology involves theoretical and methodological approaches to Architecture, Urban Planning, History, Geography, Applied Computing. Digital technologies will allow the updating and systematization of data and information of the intangible and tangible components of urban models for their incorporation into the digital medium and collaborate in their patrimonial protection. Results: conceptualization and characterization of urban models; virtual environments, database proposal.
\end{abstract}

Keywords: Traces; Fragments; Digital Technologies; Information; Urban Models

\section{INTRODUCCIÓN}

Esta ponencia plantea una propuesta teórico-metodológica para el registro, procesamiento y visualización de las huellas históricas y fragmentos arquitectónicos y urbanos de los modelos urbanos hispanoamericano y campamento petrolero instalados en la ciudad Maracaibo. El trabajo se fundamenta en la investigación Huellas históricas y fragmentos arquitectónicos y urbanos en la Maracaibo contemporánea: modelo urbano hispanoamericano y modelo de campamento petrolero, periodo 2020-2021. El objetivo general: elaborar una aproximación teóricametodológica para el análisis de los modelos urbanos hispanoamericano y de campamento petrolero para contribuir con la disciplina urbana.

Es importante su abordaje desde una perspectiva intermulti-transdisciplinar por lo complejidad del tema y la ciudad. La metodología empleada permitirá el registro y actualización de datos e información de los modelos urbanos, para actualizar el catálogo y la protección patrimonial y evitar su destrucción definitiva. Además aportará un conocimiento sobre la influencia de las culturas española y norteamericana en la Arquitectura y el Urbanismo en la ciudad, y sus huellas en el territorio. El uso de Tecnologías de Información y Comunicación en la investigación colaborará con la docencia de Arquitectura y Urbanismo. Igualmente, permitirá integrar y vincular datos e información de la evolución de Maracaibo, la reconstrucción 3D de los modelos, aportando información para su visualización y planificación de forma interactiva.

\section{MARACAIBO, LA CIUDAD CONTEMPORÁNEA}

Maracaibo es la capital del estado Zulia, está localizada en el noroeste del Lago de Maracaibo. El origen de la ciudad pertenece al periodo hispánico, siglo $\mathrm{XVI}$, posee tres fundaciones en distintos lugares a saber y dos veces abandonada. El responsable de la fundación definitiva fue
Pedro Maldonado en 1574. Guerrero (1968); Rodríguez et al (1994); Romero (1997); Sempere (2000); Urdaneta et al (2006); Petit et al (2007); Suárez (2010). La ciudad se consolidó y conservó por mucho tiempo las características de la ciudad española, luego se expandió hacia el norte, oeste y sur, cambiando su morfología en el tiempo. En la actualidad, la ciudad presenta diferentes modelos y tipologías urbanas, en ella se observan diferentes fragmentos urbanos planificados y no planificados en su territorio. (Ver Figura 1). Las intervenciones en el centro histórico no son acordes con su carácter patrimonial, la destrucción y modificación de edificios y espacios urbanos son realizadas por dependencias locales. Además de forma gradual ciudadanos y empresas transforman los antiguos campamentos petroleros instalados en Maracaibo en el siglo $\mathrm{XX}$ por parte de las empresas norteamericanas.

\section{ANTECEDENTES DE ESTUDIO}

El uso de Tecnologías de Información y Comunicación, especialmente la Informática Aplicada son utilizadas en la planificación, diseño y gestión de las ciudades generando excelentes beneficios, cada día se incrementa su utilización evidenciándose en planes urbanos y sitios web de Ayuntamientos y Alcaldías. En ese mismo orden de ideas, la digitalización en 2D y 3D, y los avances tecnológicos generados en la computación grafica tiene casi cincuenta años, y los modelos tridimensionales creados tienen su aplicación en las Disciplinas de la Arquitectura y el Urbanismo incidiendo en el proceso enseñanza-aprendizaje. (Montagú, 1999). Desde ciudades digitales disponibles de forma interactiva en línea hasta modelos virtuales de espacios urbanos de ciudades se logran, reconstruyendo sus centros históricos. Estos avances han generado cambios en los procesos de diseño y construcción de edificios y espacios urbanos, y también en la forma de observar, analizar y pensar en la arquitectura y en la ciudad. 

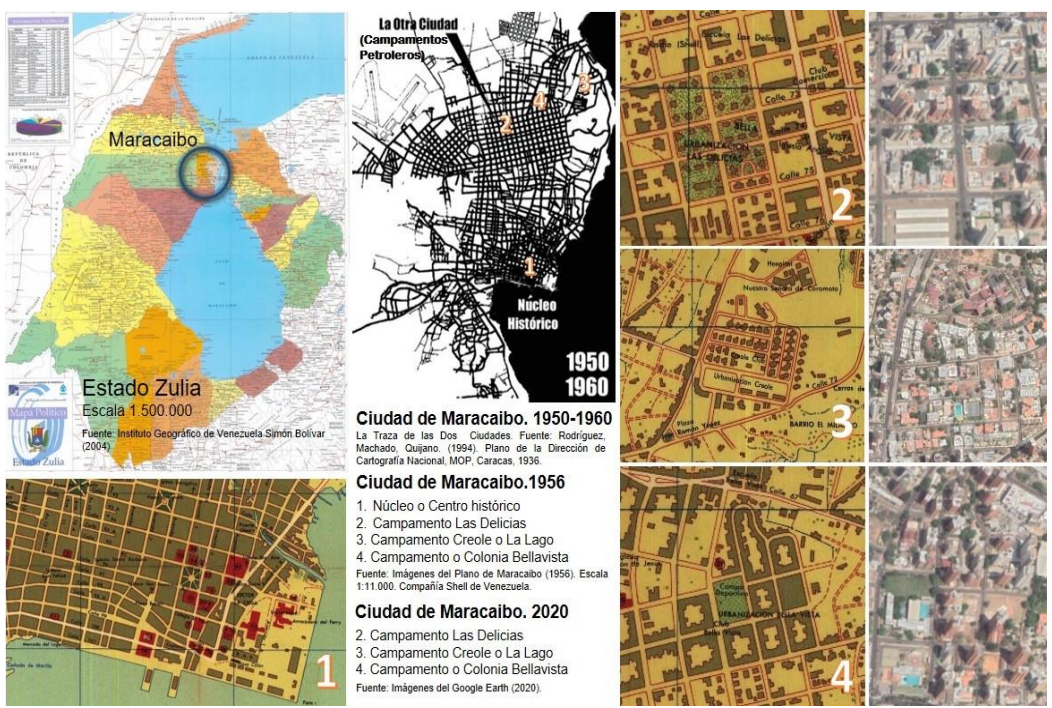

Figura 1: Modelos urbanos instalados en la ciudad de Maracaibo. Localización de la ciudad en el estado Zulia.

Fuente: Elaboración propia (2020) a partir de las fuentes indicadas.

En relación al tema, Quintanilla (2005) plantea que un análisis de la arquitectura digital en nuestro período involucra explorar el impacto de las tecnologías digitales en el desarrollo de una nueva cultura arquitectónica, fundamentado en el término "cultura" vinculado directamente con una sociedad. La cultura digital tiene diferentes significados, depende de la óptica y visión planteada desde la disciplina científica. (Lanzeni y Ardévol, 2012). Entonces, el uso de instrumentos y herramientas informáticas en la Arquitectura y el Urbanismo permitirá lograr avances significativos en este trabajo de investigación, aunque por sus altos costos está limitado su compra en el proyecto de investigación.

Con respecto a la temática de estudio en el ámbito internacional, la elaboración de ciudades virtuales y modelos de espacios urbanos se remonta al siglo XX, destacándose el trabajo pionero de la ciudad de Glasgow en Escocia, desarrollado por ABACUS de la Universidad de Strathclyde en 1980, la primera ciudad digital con un área de 25 kilómetros constituida por topografía, vialidad y aproximadamente 10.000 edificios en 3D que pueden ser consultados por Internet (Maver, Petric, Ennis, Lindsay, 2000). También, los modelos virtuales de ciudades latinoamericanas creados por la Universidad Federal de Río de Janeiro en Brasil: Río de Janeiro y La Habana. (Ripper, 2001).

El primer modelo urbano fue iniciado en la década de 1990, poseía una herramienta para la sistematización de datos que pueden ser actualizados y las nuevas formas de estudiar la ciudad y sus transformaciones urbanas. (Ripper, Vilas, 2007). Este modelo fue producto de las investigaciones del Laboratorio de Análisis Urbano y Representación Digital y se convierte en una herramienta para la Disciplina Urbana. Las actividades de la investigación se vincularon con el proyecto URBAMEDIA del profesor Arturo Montagú de la Universidad de Buenos Aires. (Ripper, Cury, 2007). El modelo de La Habana fue iniciado en el año 1995 con la finalidad de servir de hiperdocumento sobre la evolución histórica de la ciudad y sus edificaciones.

Además, se destaca los trabajos en Buenos Aires y Rosario con sistemas de interfases interactivas elaborados en VRML (Virtual Reality Modelling Language), creándose modelos urbanos 2D, 3D, 4D, 5D, los cuales podían ser consultados en un sitio web. (Castañe, 2007). Igualmente, el modelo urbano del área fundacional de Santa Fé La Vieja, también en Argentina (Stipech, Bredanini, Chiarella (2007), entre otras. En el ámbito nacional, se destacan los trabajos realizados en Arquitectura y Urbanismo por la Facultad de Arquitectura y Diseño de la Universidad del Zulia, el proyecto se llamaba BLPG (Barcelona, Puerto La Cruz, Lechería y Guanta) localizado en el estado Anzoátegui.

En el trabajo planteó una metodología de análisis urbano con el uso del lenguaje VRML vinculado un ambiente virtual interactivo 3D con un Sistema de Información Georeferenciados (ArcView®)". (Burgos y col, 2006: p.49). Igualmente, se destaca el Proyecto Hipermedial de la ciudad de Maracaibo, un sistema integral constituido por cinco modelos cibernéticos de la ciudad digital, incluye el estudio de los proyectos de arquitectura y planificación urbana de la ciudad, las simulaciones virtuales, bases de datos de los edificios de la ciudad, también información urbana para el trabajo colaborativo entre diseñadores y planificadores. Los programas como AutoCAD, 3DMax, VRML, MS Access, Dbase IV, MS Visual Fox, MS SQL, ESRI ArcViewGIS, entre otros, se usaron en la investigación. (Cuberos, Indriago, 2002).

En las áreas donde se localizan los modelos de estudio se consideran los trabajos realizados desde 1999 hasta la actualidad por la Autora. En ese mismo orden de ideas, entre 1999 y 2011 se generó una experiencia docente en la cátedra de Computación Gráfica II mediante el uso de los Sistemas CAD, generándose "vistas, imágenes, archivos gráficos, los cuales representaron "modelos 
virtuales similares a la realidad". (Espina, 2001, p.138). Además se crearon "representaciones fotorealísticas de proyectos arquitectónicos existentes e inexistentes, los cuales han desaparecido de la memoria de la ciudad y sólo quedan registros en formato analógicos, algunos de ellos formaba parte del patrimonio histórico de la Modernidad de Maracaibo. (Espina, 2001: p.140).

En el año 2002, Espina desarrolló una investigación cuyo objetivo fue elaborar una Base de Datos para el "registro de la información sobre la arquitectura moderna en el período 1920-1990 de Maracaibo, mediante el diseño de una herramienta automatizada para organizar la data relacionada con los edificios, parcelas y proyectistas de la ciudad". En la investigación se aplicó la gráfica digital al trabajo realizado por las arquitectas Elisa Quijano, María Machado y Ethel Rodríguez de "La Otra Ciudad, la génesis de la ciudad petrolera de Maracaibo" realizado en 1994.

Igualmente, entre los años 2005 y 2007 se ejecutaron varias investigaciones vinculadas con el centro histórico de la ciudad generándose modelos o entornos virtuales del espacio público Plaza Baralt de Maracaibo. En primer lugar la construcción de la Memoria Urbana de Plaza Baralt, en segundo lugar la Reconstrucción del Espacio Urbano y la tercera Simulación en el espacio urbano. Uno de los mayores aportes de este trabajo es la "incorporación de herramientas para la planificación y diseño de espacios urbanos. La herramienta digital estaba constituida por "modelos tridimensionales virtuales del espacio urbano, con elementos de ambientación coincidentes con las actividades propias del sitio, incorporando el uso de avatares, sonidos, videos y animaciones". (Espina y col, p. 056). El uso del entorno multiusuario permitió la interacción entre modelo y usuarios mediante avatares, y como herramienta para el diseño, la planificación y trabajo en redes en espacios urbanos de carácter patrimonial, en este caso la Plaza Baralt de la ciudad. (Figura 2).

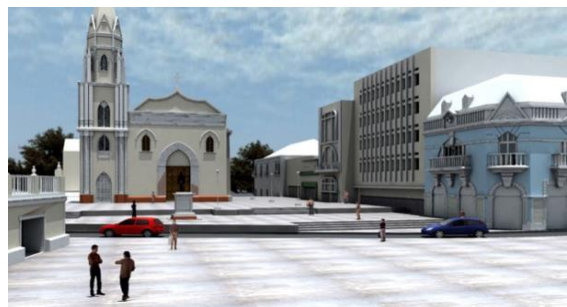

Figura 2. Entorno virtual de la Plaza Baralt de Maracaibo, escenario siglo XX. Fuente: Espina y col. (2006).

Finalmente, en el año 2012 se desarrollaron trabajos con los estudiantes de la Cátedra de Urbanismo en el Campamento Colonia Bellavista, realizándose el levantamiento fotográfico de las edificaciones del antiguo campamento y se crearon los modelos tridimensionales del enclave residencial. (Espina, 2012). En el desarrollo de la cátedra se constató que la aplicación de Tecnologías de Información y de Comunicación, "apoyó la comprensión de principios y mecanismos en la construcción y análisis de la ciudad, propósito de la unidad curricular, igualmente permitió fortalecer la investigación y expresividad en los estudiantes, cumpliendo las competencias exigidas en la carrera de Arquitectura". (p.295).

\section{METODOLOGIA}

\section{FASES DE LA INVESTIGACION}

En el desarrollo de la investigación se plantean siete fases por la complejidad de los modelos urbanos de estudio, la escasa y dispersa información planimétrica en los primeros siglos del modelo hispano y la extensa revisión que se está realizando en las fuentes documentales e históricas. Las fases se describen a continuación: Fase I: propuesta teórica-metodológica para la construcción de los modelos urbanos reales y virtuales; Fase II: revisión de antecedentes de trabajos e investigaciones vinculadas con la temática de estudio, teorías sobre el diseño y construcción de modelos; revisión de programas para el diseño de escenarios, avatares, agentes y actores; Fase III: recolección, análisis y sistematización de los datos representativos de la evolución urbana de la ciudad, con los datos de modelos urbanos: viviendas, edificios, espacios públicos importantes y mobiliario urbano. También, revisión de planos analógicos y cartografía histórica. Fase IV: Levantamiento fotográfico y cartográfico, reconstrucción gráfica de los modelos de edificios en $2 \mathrm{D}$ y $3 \mathrm{D}$ de modelos urbanos, revisión de fuentes documentales.

En la Fase $V$ se realiza el análisis de componentes de los modelos, la propuesta de las bases de datos gráfica y alfanumérica; en la Fase VI: modelos urbanos reales y virtuales: caracterización morfológica de los elementos de ambientación y modelado, generación de vistas renderizadas y animaciones de los modelos urbanos; Fase VII: análisis y discusión de los resultados obtenidos en los modelos reales y virtuales.

Cabe destacar el uso de la base cartográfica disponible de las Instituciones del Estado en primera instancia, la cual será actualizada en sitio con la ayuda de imágenes satelitales y equipos tecnológicos. Igualmente se realizará el análisis formal y espacial de los componentes de los modelos para su representación en formato digital. Se incorporará el uso de las imágenes del siglo XIX, XX y las actuales, pues en algunas áreas de los modelos las edificaciones fueron destruidas, pero algunos elementos del modelo urbano aún se conservan en la estructura urbana del centro histórico y las urbanizaciones petroleras.

\section{PROPUESTA TEÓRICA-METODOLÓGICA: UNA APROXIMACIÓN}

En el proyecto se utilizan diversos enfoques teóricos $y$ metodológicos para abordar la investigación de forma integral desde la Arquitectura, Urbanismo, Historia, Geografía y la Informática Aplicada; especialmente los métodos de la investigación descriptiva e histórica son importantes en el análisis de las edificaciones históricas. Además, en este trabajo se utilizan procedimientos y métodos empleados en previas investigaciones de la ciudad. (Espina 1999, 2005, 2007, 2009a, 2009b, 2012). Con respecto a los métodos de la investigación cualitativa y cuantitativa se utilizan en los procesos de registro, sistematización y análisis de los datos e información de modelos urbanos y estudio de la evolución histórica de la ciudad, pues el modelo hispano se remonta a la fundación de la ciudad y el modelo campamento petrolero al siglo XX. 
El uso del método cualitativo es importante en el trabajo, pues no se tiene información actualizada de algunas edificaciones pertenecientes a los campamentos petroleros, y con respecto al modelo hispano, muchos datos e información están dispersos en diferentes fuentes escritas. Adicionalmente, en el trabajo de campo cualitativo se realizará con distintas técnicas etnográficas, tales como historias de vida, tradición oral, entre otros. Igualmente, se utilizan métodos de la investigación descriptiva: observación directa, observación documental, la entrevista no estructurada, entre otros.

En la observación directa se deben actualizar y comparar los componentes de los modelos urbanos originarios con los existentes. En la aplicación de la entrevista estructurada y no estructurada se aplicará en aquellas personas que vivieron en el centro histórico y en las antiguas colonias petroleras. También, el empleo de la investigación histórica permite abordarla desde un punto de vista inter-multi-transdiciplinar por lo complejo de la temática de estudio. Los planteamientos anteriores están fundamentados en Amodio (2005, p.13), "la construcción de un tema de investigación deriva de múltiples factores y exigencias, determinados principalmente por intereses y necesidades que cada momento histórico expresa". Por lo tanto, en esta investigación se seleccionaron aquellos orientados hacia los objetivos de la investigación.

\section{MODELOS URBANOS HISPANOAMERICANO Y DE CAMPAMENTO PETROLERO}

La ciudad de Maracaibo está constituida por diferentes fragmentos de diversos periodos históricos, en ella algunos de los componentes de los modelos urbanos hispanoamericano y campamento petrolero todavía preexisten. En la Tabla 1 se presentan los modelos urbanos instalados en la ciudad con los componentes propuestos en esta investigación.

Tabla 1: Modelos Urbanos instalados en Maracaibo. Fuente: Elaboración propia (2020) datos obtenidos de Romero (1997), Sempere (2000, Pirela (2007), Suarez (2010).

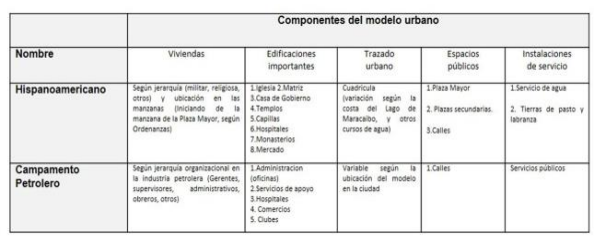

\section{MODELO URBANO HISPANOAMERICANO}

El modelo urbano de la ciudad hispana instalado en el siglo $\mathrm{XVI}$ en Maracaibo, en general puede identificarse como un "modelo clásico de la ciudad hispanoamericana" con variaciones en la aplicación de las normativas o Leyes de Indias; lo anterior está fundamentado en los planteamientos de Jorge Hardoy (1968), el indica que se instaló en América a partir de la llegada de los europeos al continente. (Hardoy, 1968 en Terán 2002, p. 13). Al respecto Terán (2002) señala que en algunos casos se realizaron variaciones del modelo oficial constituido en las Ordenanzas de 1573 o Felipe II.

Sin embargo, Semper (2000) indica las Ordenanzas de descubrimiento, nueva población y pacificación fueron aprobadas por Felipe II en junio de 1573, es difícil suponer que ellas afectaron directamente la planta de la fundación, pues se crearon un año antes de la fundación de Pedro Maldonado, y es cierto que ésta presenta muchos elementos contenidos en las llamadas Leyes de Indias. Sempere (2000), señala que "ambas fueron el producto de casi tres cuartos de siglo de experiencia en nuevas fundaciones, tiempo durante el cual se debieron producir soluciones rápidas y sencillas definiéndose una práctica que constituía el bagaje que cada nuevo fundador llevaba consigo" y posteriormente fue sistematizada en las Ordenanzas de Felipe II. (Sempere, 2000, p. 26).

Luego a partir de la cuadricula, la ciudad inicia su crecimiento en los próximos siglos, hacia el norte con la avenida El Milagro y hacia el sur con la avenida Los Haticos, donde se construyen los hatos para la instalación de las residencias de los comerciantes europeos. Sempere (2000) señala que estuvo condicionada por la ocupación de la costa y por el Sistema de Caminos Reales, uno de ellos fue el Camino Real Rio Hacha Por su parte, Pirela (2007, p. 35) indica que el "crecimiento físico de Maracaibo había quedado sugerido por las tendencias de los dos polos norte-sur que conformaron el primer ensanche".

\section{MODELO DE CAMPAMENTO PETROLERO}

Durante el crecimiento y expansión de la ciudad en los años 20, 30 y 40, se genera nuevas áreas que Sempere (2000, p. 297) denominó El Ensanche, allí se instaló una nueva modalidad de asentamiento denominado campo petrolero, el cual era una "unidad cerrada tato física como socialmente que contaba internamente con todos los servicios y amenidades propias de las nuevas formas de vida". Adicionalmente, "los nuevos campos se asentaron a lo largo de ejes en sentido este-oeste que conectaban la avenida de El Milagro con Bellavista y Las Delicias". El modelo de campamento petrolero fue instalado por las compañías norteamericanas en las diferentes ciudades del país. Autores como Rodríguez, Machado y Quijano, denominaron esa área, La Otra Ciudad. En la Tabla 2, se observan los nueve campamentos petroleros instalados en Maracaibo y sus características, éstos presentaban características similares pero con algunas variaciones.

Tabla 2: Modelo Urbano de Campamentos Petroleros instalados en Maracaibo. Fuente: Elaboración propia (2020) datos obtenidos de Romero (1997), Sempere (2000), Pirela (2007), Suarez (2010).

\begin{tabular}{|c|c|c|c|c|c|}
\hline & \multicolumn{5}{|c|}{ Campamentos petroleros en la Maracaibo, estado Zulia } \\
\hline Nombre & $\begin{array}{l}\text { Fundacicin } \\
\text { (Año) }\end{array}$ & $\begin{array}{l}\text { Compaña } \\
\text { (fundación) }\end{array}$ & $\begin{array}{l}\text { Companiala } \\
(\text { Siglo XX) }\end{array}$ & $\begin{array}{l}\text { Condicín } \\
\text { (Siglo } X X)\end{array}$ & $\begin{array}{l}\text { Uscos (actvidac) } \\
\text { (Siglo XX) }\end{array}$ \\
\hline $\begin{array}{l}\text { 1.Colonia } \\
\text { Bellavista }\end{array}$ & 1930 & Canbbean/Shell & (sin datos) & $\begin{array}{l}\text { Urbano. Vendido } \\
1955\end{array}$ & $\begin{array}{l}\text { ResidencalAlla } \\
\text { Geercia, Sevicios }\end{array}$ \\
\hline 2. Las Delicias & 1928 & Royal Dutch-Shell & (sin datos) & Urbano & Resdencialsevicios \\
\hline 3. Los Haticos & 1958 & Canbbean/Shell & Plivado & Urbano & $\begin{array}{c}\text { Resdencial } \\
\text { (corffirma ofros usos) }\end{array}$ \\
\hline 4.LaAreaga & 1928 & Creole & LAGOVEN & Uibano & $\begin{array}{c}\text { Resdencial } \\
\text { (confirma ortos usos) }\end{array}$ \\
\hline $\begin{array}{l}\text { 5.La Richmond, } \\
\mathrm{Km2}\end{array}$ & 1946 & $\begin{array}{l}\text { Richmond-Chevoon } \\
\text { Pamaven }\end{array}$ & $\begin{array}{l}\text { Palmaven' } \\
\text { COFPOVEN }\end{array}$ & $\begin{array}{l}\text { Staft Vendido en } \\
1961\end{array}$ & $\begin{array}{l}\text { Resdencial } \\
\text { (corfirmar oros usos) }\end{array}$ \\
\hline 6. La Lago & 1931 & Cresle & (sindatos) & $\begin{array}{l}\text { Urbano, Vendido } \\
1958\end{array}$ & $\begin{array}{l}\text { Residencial } \\
\text { Servicos }\end{array}$ \\
\hline 7.ElMilagro & 1932 & $\begin{array}{l}\text { Menegarde } \\
\text { Gulf oil }\end{array}$ & (sin datos) & $\begin{array}{l}\text { Urbano. Vendido } \\
1957\end{array}$ & $\begin{array}{l}\text { Residencial Oricinas } \\
\text { Servicics (muelles) }\end{array}$ \\
\hline 8.Gabaldon & 1950 & Creole & (sindatos) & $\begin{array}{l}\text { Urbano Vendido } \\
953\end{array}$ & (sindatos) \\
\hline $\begin{array}{l}\text { 9.Vilialobos } \\
\text { (Poniente) }\end{array}$ & 1922 & (sin datos) & (sin datos) & $($ sin datos) & (sin datos) \\
\hline
\end{tabular}

Según Romero (1997) "los campamentos residenciales petroleros se conciben como recintos urbanos cerrados, autónomos e independientes de la administración local. Operan como enclaves que no se integran a las poblaciones naturales inmediatas al yacimiento". Además, "el concepto de comunidad cerrada prevalecerá sin 
variación hasta la década de 1950". Romero (1997, p. 14). Entre 1927 y 1950 "fueron concebidos para satisfacer las necesidades de habitación y servicios requeridos por la población encargada de la actividad petrolera sin establecer relaciones urbanas con su entorno. La racionalidad de su trazado urbano, la infraestructura de redes y servicios, así como la formalización y sistematización de su arquitectura, demuestran la presencia de un urbanismo definitivamente moderno." (p.78).

Uno de las características de los campamentos fue la construcción de viviendas según los niveles gerenciales, los cuales "se distinguen por la extensión y el paisajismo de las parcelas sobre las cuales se emplazan distintas tipologías de viviendas asociadas a los roles empresariales del residente". Las colonias Shell, Bella Vista y Las Delicias en Maracaibo presentan "tipologías de viviendas de una y dos plantas, repitiendo el esquema simétrico y de galerías o terrazas con vista a la calle, y con cubiertas livianas resueltas a cuatro aguas y dos aguas". (Romero, 2011, p.87). Pirela (2007) señala que los enclaves petroleros se localizaron en "ventajosas orientaciones respecto a los vientos, fueron trazados con novedosos urbanismos, con viviendas prefabricadas o diseñadas especialmente para el trópico y con un concepto cerrado y una organización jerárquica de la comunidad". Estos enclaves tenían servicios como clubes, tiendas por departamento, hospitales, oficinas, entre otros.

En el modelo urbano, las colonias Bella Vista y Las Delicias fueron creadas por la Empresa Shell al norte de Maracaibo, aprovechando las condiciones ambientales favorables para albergar residencias, servicios administrativos y comunitarios. "En la colonia Las Delicias destacan el edificio Las Laras, sede de la oficina principal; el edificio Los Chaguaramos, donde funcionaban los laboratorios, y el Centro Médico de Occidente". Adicionalmente, se incorporaron los servicios con la escuela primaria, hoy Colegio Claret, junto a una iglesia. La Empresa Creole fundó su "colonia residencial en el sector La Lago, integrado con similares facilidades administrativas y sociales, destacando el edificio del club junto al moderno Hospital Coromoto". (Romero, 2011, p.85-86). En la figura 3 se observa el modelo urbano tridimensional de la Colonia Bellavista, también el plano y algunas imágenes de las viviendas existentes en el antiguo enclave residencial.
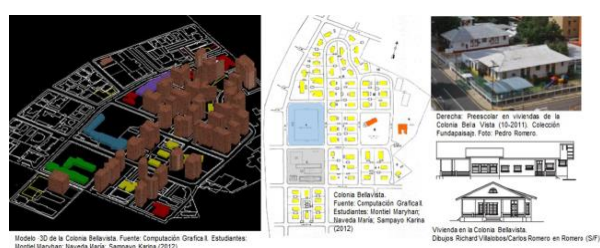

Figura 3. Campamento Colonia Bellavista. Fuente: Elaboración propia (2020) datos obtenidos en las fuentes indicadas.

\section{TECNOLOGIAS DE INFORMACION Y COMUNICACION}

La problemática actual que presentan los espacios urbanos y la ciudad de Maracaibo, requiere un mayor aporte de conocimientos de la Disciplina Urbana y de la Informática Aplicada. Es allí, donde el uso de las tecnologías digitales en proyectos de arquitectura y urbanismo e investigaciones pueden mejorar el análisis y comprensión de la evolución histórica de la ciudad, Además el conocimiento de los modelos urbanos que conforman la ciudad permiten comprender su diseño y planificación original. Aunque se está trabajando con el entorno actual de los modelos urbanos, es fundamental construir algunos escenarios en $2 \mathrm{D}$ para reconstruir el modelo original hispano y campamento petrolero, para luego establecer comparaciones con los modelos actuales y analizar los elementos que aún existen en la estructura urbana, las edificaciones y viviendas.

Con respecto al modelo hispano de la ciudad de Maracaibo, se poseen los primeros dibujos o croquis del poblado o La Villa de Maracaibo elaborados por Rodrigo de Arguelles y Gaspar de Párraga entre 1574 y 1579. Igualmente, se revisan informes de cronistas, relatos de viajeros e historias de vida, imágenes de cartografías y mapas antiguos originales disponibles en el Acervo Histórico del Zulia, Academia de Historia, Archivo de Indias de Sevilla en España; entre otros. En el análisis de los componentes del modelo hispano se están revisando otros planos y cartografías antiguas para construir el modelo original. Para lo cual se consideran los planteamientos de Terán (2002, p.13), en el uso de "estos planos como puede identificarse los elementos componentes del "modelo clásico" y sus características más determinantes del modelo: la cuadricula como forma modulada de organización del espacio, crecedera, extensible". Además, "la plaza cuadrada central, resultado de dejar una manzana vacía, equivalente a un modelo de la cuadricula".

Sin embargo, solo se han localizado planos de la ciudad del siglo XIX, por lo tanto existen vacíos de información para el levantamiento de algunos componentes o partes del modelo original. En relación al modelo campamento petrolero se están revisando los planos e imágenes disponibles en las publicaciones de la industria petrolera. Además, se realiza el estudio de las tipologías urbanas del campamento pues en la actualidad se observan unión de lotes o parcelas, y la desaparición de viviendas tipos.

Entonces en ésta investigación se seleccionaron los planos de las propuestas hipotéticas de Sempere (2000) de los siglos XVI, XVII, XVIII e inicios del XIX y Suárez (2010) para completar los componentes y elaborar el análisis de la estructura urbana de los modelos urbanos. En relación a los trabajos de Espina (2009a, 2009b) se seleccionó la reconstrucción del espacio urbano Plaza Baralt 3D localizado en el centro histórico, incluye edificios, mobiliario urbano, ambientación, avatares etc.; diferenciando los datos e información obtenida para una primera aproximación de los modelos.

\section{INFORMACION, PROCESAMIENTO Y VISUALIZACION. CONCEPTUALIZACION DE LAS BASE DE DATOS RELACIONAL}

Los datos son el elemento fundamental de las bases de datos de cualquier tipo. Durante los últimos años se han desarrollado bases de datos vinculadas a viviendas y edificaciones de la ciudad. En esta investigación, el proceso de recolección y sistematización de datos requiere de tiempo y se convierte en proceso de búsqueda muy complejo cuando están vinculados con insuficiencia de planos, cartografías, fotografías de los modelos urbanos. Los datos existentes están dispersos en diferentes fuentes, 
por lo tanto en el proyecto de utilizarán algunos instrumentos análogos y digitales para la obtención de coordenadas en sitio y la georefenciación de los datos con las cartografías digitales, mediante teléfonos inteligentes y Global Positioning System (GPS).

Además, se trabajará con fotografías análogas y digitales desde finales del siglo XIX hasta la actualidad, mediante el uso del programa Adobe Photoshop para edición de fotografías y planos de los siglos XVIII, XIX, XX y realizar su conversión al medio digital. Igualmente, las fotografías aéreas actuales y de edificaciones provenientes de Google Earth son empleadas en la investigación, las cuales aportan un recurso importante para el estudio de la estructura urbana de la ciudad; sin embargo, existen muy pocos edificios en 3D están disponibles.

En relación al trabajo de Base de Datos para el "registro de la información sobre la arquitectura moderna en el período 1920-1990 de Maracaibo, se seleccionó la Base de Datos de los registros históricos, formales, espaciales y técnicos, y los modelos 3D de las edificaciones y parcelas de edificaciones patrimoniales. Las nuevas bases de datos propuestas están se fundamentadas en el Modelo EntidadRelación de Chen (1976) para describir entidades, atributos y relaciones. Además, se realizará el Proceso de Normalización y trabajará con Microsoft Access inicialmente. A partir de las bases de datos creadas en esta investigación se seleccionarán los datos e información digitalizada de las edificaciones de Maracaibo localizadas en el campamento petrolero. En la actualidad de estudian otros manejadores de bases de datos para seleccionar el programa de computación idóneo para el registro y almacenamiento los datos, se plantea el MS SQL.

\section{MODELOS O ENTORNOS VIRTUALES VS. ENTORNOS REALES}

Los modelos urbanos virtuales planteados estarán constituidos por componentes generados en las investigaciones previas de la autora. Inicialmente en la investigación se plantea elaborar los modelos urbanos virtuales con los Sistemas CAD para digitalizar algunos nuevos componentes de modelos urbanos en $2 \mathrm{D}$ y $3 \mathrm{D}$, sin embargo se plantea el uso de Autodesk Revit para una representación fotorealística de los elementos de ambos modelos urbanos, con el soporte de fotografías aéreas y el relevamiento en sitio, además la georreferenciación de los puntos más importantes de la edificación con la base cartográfica en $2 \mathrm{D}$ de la ciudad perteneciente a la institución local, fundamentado en coordenadas Norte y Este.

En relación al modelado del territorio y ambientación todavía está en proceso de análisis para vincular las bases de datos relacional propuestas: viviendas, edificios, la estructura urbana, incluyendo los espacios públicos, instalaciones de servicio, entre otros, con los modelos urbanos 3D del territorio. Al respecto, se están analizando más opciones de programas de computacion y otros avances tecnológicos. Es relevante el uso de drones en la actualización de datos en sitio para la investigación, pero lamentablemente existen restricciones para uso en la ciudad por parte de las instituciones del estado.

En primer término, algunos modelos virtuales generados en la cátedra de Computación Grafica II, como el Edificio
Las Laras, es un componente del campamento petrolero y en la actualidad es la sede del Centro de Arte PDVSA La Estancia. En segundo término, el análisis urbano realizado, la base cartográfica, modelo urbano del campamento y viviendas de la antigua colonia elaborados en la Catedra de Urbanismo en el 2011. Además, está en análisis el empleo del entorno multiusuario (mundo virtual) en ambos modelos pues se tienen un espacio urbano ya construido en esa plataforma en una investigación anterior, pero habría que actualizar los modelos y las versiones de los programas de computación. Luego de este estudio, se decidió utilizar los plugin y navegadores más utilizados para VRML, el Java y sistema Cliente - Servidor de código abierto y licencia GPL. Por consiguiente, se usará parte de la plataforma tecnológica ya creada, la cual puede observarse en las Figuras 4 y 5.

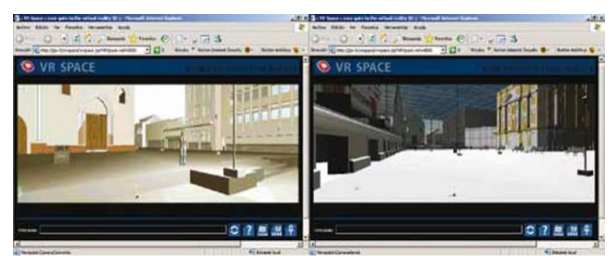

Figura 4. Vistas del mundo virtual de la Plaza Baralt de Maracaibo. Fuente: Espina, Oliva (2007).

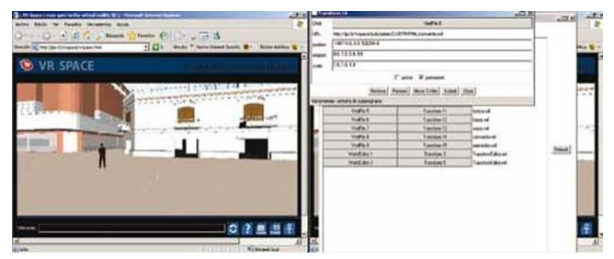

Figura 5. Vistas del mundo virtual multiusuario: Interfaz de edición Fuente: Espina, Oliva (2007)

Los programas VRSpace, BingBang Data, MUSE (Multiuser Simulation Environment), Blaxxun Contact, también se están estudiando otros programas de computación recomendados para la generación de los modelos urbanos 3D del periodo actual y su incorporación el entorno o mundo virtual.

\section{RESULTADOS}

La investigación generará diversos resultados: 1) propuesta teórico-metodológica para el análisis de modelos urbanos, la cual ayudará en la docencia en las Cátedras de Ecología y Ambiente Urbano, Urbanismo y Diseño Urbano; 2) registro y sistematización de datos e información de modelos de estudio con sus fichas técnicas en formato digital; 3) primeros entornos virtuales de modelos hispanoamericano y de campamento petrolero; 4) análisis comparativo de los modelos; y 5) propuesta de bases de datos. Es importante destacar que en la actualidad se está estudiando los programas de computación AutoCAD Map3D, la metodología de Building Information Modeling (BIM) para manejar la información de los componentes de los modelos urbanos. Sin embargo el proyecto de investigación tiene limitaciones en la adquisición de equipos y herramientas tecnológicas por la carencia de recursos económicos para el desarrollo del proyecto de investigación. 


\section{DISCUSIÓN Y CONCLUSIONES}

\section{HUELLAS HISTÓRICAS Y FRAGMENTOS ARQUITECTÓNICOS Y URBANOS EN MARACAIBO}

En la planificación y gestión de ciudades hispanoamericanas, existe una renovada reflexión por expertos sobre la fundación, evolución y la problemática existente generada por la modificación de sus centros históricos. Sanz (2004, p. 24) indica que la ciudad hispanoamericana actual, al igual que sucede con muchas ciudades del planeta, tiene una problemática muy diversa. Para Terán (2002, p. 9) en los últimos tiempos se ha producido un considerable aumento de conocimientos disponibles acerca de la ciudad hispanoamericana lo cual genera avances significativos en el estudio de su fundación. Por consiguiente este trabajo aportará un conocimiento actualizado sobre los componentes de ambos modelos urbanos, ya que algunos de ellos han sido sustituidos por edificaciones modernas sin considerar su carácter patrimonial.

En relación al modelo urbano hispanoamericano se mantienen algunas manzanas y parcelas, específicamente las que rodean la Plaza Bolívar, también la ubicación original de algunas edificaciones pero con transformaciones realizadas en el tiempo, se destacan: la Catedral de Maracaibo, la Iglesia Matriz, la Casa de la Capitulación, El Palacio de Gobierno, entre otros; también existen una o dos casas coloniales que están muy deterioradas, las cuales deben revisarse en el trabajo de campo para verificar su condición actual; en algunas casos se construyen copias de viviendas de siglos anteriores en áreas del modelo. Se está realizando un trabajo exhaustivo en planos, fotografías y fuentes documentales de carácter histórico.

Con respecto al campamento petrolero, los nueve enclaves residenciales pertenecientes a las empresas norteamericanas, cuyo funcionamiento y mantenimiento se realizaba según las normas de las empresas, luego de cambiar su condición como enclave petrolero en el siglo XX a privada, la destrucción ha sido progresiva, el proceso de sustitución de viviendas, modificación de edificaciones de servicio, y la unificación de parcelas avanza de manera vertiginosa. Aunque se mantienen algunas edificaciones como el Hospital Coromoto y el Centro Médico de Occidente. Lo anterior, significa pérdida de la identidad de Maracaibo, destrucción de la memoria histórica de los espacios urbanos y la misma ciudad. Por lo tanto, la realización de investigaciones similares puede colaborar en el registro y catalogación de los inmuebles y espacios urbanos existentes, especialmente las huellas urbanas con una importancia significativa y trascendental.

Finalmente, es importante considerar los planteamientos de Deina y Balmaceda (2000) en relación a la conservación del patrimonio, en donde la "reconstrucción virtual de una ciudad es patrimonio digital porque considera la morfología, calidad y cualidad de espacios que ya no existen e investiga en la forma de percibir el espacio en el momento histórico en el cual se concibió". Entonces, al "recrear en un escenario virtual los espacios ya desaparecidos, se reconstruye de alguna forma las características morfológicas y especiales no solamente del espacio urbano sino también del individuo de esa época".

\section{TECNOLOGIAS DE INFORMACIÓN Y LAS CIUDADES}

Las tecnologías digitales pueden ayudar a las reconstrucciones arquitectónicas y urbanas de la ciudad de Maracaibo, también colaborar con la catalogación y preservación de los componentes existentes de los modelos urbanos hispanoamericanos y campamento petrolero, especialmente por la dispersión de datos en fuentes documentales, la escasez de planos, grabados o dibujos de ambos modelos. En el caso del modelo hispano de Maracaibo se han construido hipótesis sobre el plano fundacional pues no se han encontrado mapas o cartografías antes del siglo XIX, los cuales se trasladan al medio digital. Con respecto a la información del enclave petrolero ha sido difícil localizar la planificación, diseño y construcción original pues los datos en formato análogo corresponden al siglo $\mathrm{XX}$ y existen restricciones en el acceso a las fuentes documentales en la industria petrolera; sin embargo también se está digitalizando en $2 \mathrm{~d}$ y 3D. El conocimiento y análisis de modelos urbanos existentes en la ciudad, significa reconstruir y rastrear su historia, forma y transformación urbana. Es importante señalar las limitaciones en la actualización de los datos de los modelos urbanos por la situación actual en el país, la cual ha restringido el levantamiento de información en campo.

\section{REFERENCIAS}

Espina, J. (2001). La Tecnología Digital en las Edificaciones Arquitectónicas de la Modernidad". 2da Conferencia Venezolana sobre Aplicaciones de Computadoras en Arquitectura, CONVEACA. Universidad del Zulia. Facultad de Arquitectura. Fecha: 05 al 07 de Diciembre de 2001.

(2002). Base de datos de la arquitectura moderna de la ciudad de Maracaibo 1920-1990. VI Congreso de la Sociedad Iberoamericana de Gráfica Digital, SIGRADI 2002. Universidad Central de Venezuela. Facultad de Arquitectura y Urbanismo. Fecha: 27 al 29 de Noviembre de 2002. pp. 133139.

Espina, J., y col. (2005). Reconstrucción del espacio público urbano Plaza Baralt. Proyecto de Investigación. CONDES. Universidad del Zulia.

Espina y col (2006). Entornos virtuales y su interconectividad en la web para la Planificación Urbana. X Congreso Iberoamericano de Gráfica Digital, SIGRADI 2006. Universidad de Chile, Santiago de Chile-Chile. Fecha: 21 al 23 Noviembre de 2006. pp. 350-354.

Espina, J., Oliva, J. (2007). Espacios urbanos, entornos multiusuarios y su interconectividad en la web. RevistaDe arquitectura, No.15, pp. 057-060. Primer semester. Facultad de Arquitectura y urbanismo de la Universidad de Chile, Chile.

Espina, J. (2007). Espacio urbano Plaza Baralt. Entornos Virtuales y su interconectividad en la WEB. Capítulo 7 del libro. URBAMEDIA. Base de datos urbanos de áreas centrales, casos de ciudades argentinas y latinoamericanas. Facultad de Arquitectura, Diseño y Urbanismo. Universidad Nacional de Buenos Aires. (pp. 123-139). Argentina.

(2009a). Memoria Urbana de la Plaza Baralt: propuesta para su rescate". XIII Congreso Iberoamericano de Gráfica Digital, SIGRADI 2009. FAU Universidad de Presbiteriana Mackenzie. Fecha: 1617 y 18 de Noviembre del 2009.

(2009b). Aproximación Teórica-Metodológica para la construcción de la Memoria Urbana de la Plaza Baralt. Trabajo de Ascenso para optar a la categoría de Profesor Asociado. Facultad de Arquitectura y Diseño. Universidad del Zulia. Maracaibo, Venezuela. (pp.333). 
(2012). Procesos, Metodología y Prácticas en Urbanismo: flujo continuo de datos e información en sectores urbanos de la ciudad. SIGRADI 2012 | FORMA (IN) FORMAÇÃO.

(2020). Huellas históricas y fragmentos arquitectónicos y urbanos en la Maracaibo contemporánea: modelo urbano hispanoamericano y modelo de campamento petrolero. Proyecto de Investigación. Instituto de Investigaciones. Facultad de Arquitectura y Diseño.

Burgos, I. Bustos, G., González, M., Oliva, J. (2006). Interactividad Urbana 3D: SIG + VRML. (2006). Revista Iberoamericana de Sistemas, Cibernética e Informática (RISCI). Volumen 3Numero 1 - Año 2006. Obtenido en https:/vdocuments.mx/document/ interactividad-urbana-3dsig-vrml-ivan-v-burgos-riscipdfsc234expdf.html.

Castañe, D. (2007). Buenos Aires y Rosario, análisis de producción de sistemas de interfaces interactivas. Capítulo del libro. URBAMEDIA. Base de datos urbanos de áreas centrales, casos de ciudades argentinas y latinoamericanas. Facultad de Arquitectura, Diseño y Urbanismo. Universidad Nacional de Buenos Aires. (pp. 53-74). Argentina.

Chen, P. (1976). The Entity-Relationship Model--Toward a Unified View of Data. Massachusetts Institute of Technology. Cambridge.ACM-ACM-Press. (pp. 9-36).

Cuberos, R., Indriago, J. (2002). Hypermedia approaching to digital cities. 3D Maracaibo Project. ECAADE 20 [design education] Information Processes in Design. Session 11. Obtenido

https://academia.edu/18953644/Hypermedia_approaching_to _digital_cities_3D_Maracaibo Project.

Deina, S. y Balmaceda, M.: 2000, La ciudad intangible, SIGRADI, Brasil, pp. 182-187.

Guerrero, F. (1968). En la ciudad y el tiempo. Tomo I. Tipografía Excelsior. Maracaibo, Venezuela.

Lanzeni, D. ArdévoL, E. (2012) Visualidades y materialidades en la cultura digital: Caminos para transitar la diferencia. Ponencia para el seminario Diversidad cultural y nuevas tecnologias: Casos y propuestas para una agenda de investigación, Red Vicom, Aecid. Lima, 30 de mayo, 2012.

Maver, T., Petric, J., Ennis, G., y Lindsay, M. (2000). Visiting the Virtual City, SIGRADI, Brasil, pp. 135-139.

Montagú, A. (1999). DATARQ 2000. Base de Datos de la Arquitectura Moderna y Contemporánea. Universidad de Buenos Aires, Facultad de Arquitectura, Diseño y Urbanismo, Centro CAO. Editorial Terra. Buenos Aires. 200 pp.

Montagú y col. (2002). URBAMEDIA desarrollo de una base de datos de fragmentos urbanos de ciudades argentinas y latinoamericanas utilizando tecnología digital "VRML" (Virtual Reality Modelling Language). Centro CAO Facultad de Arquitectura, Diseño y Urbanismo.Universidad de Buenos Aires. VI Congreso de la Sociedad Iberoamericana de Grafica Digital, SIGRADI 2002. Caracas-Venezuela.

Petit, N., Pineda, E. y Quijano, E. (2007), La Maracaibo hispana. Fundación y expansión de una ciudad-puerto. Venezuela, siglos XVI-XVIII. Procesos Históricos. Artículo arbitrado. ISSN 1690-4818. Año 6, No 12. Segundo Semestre 2007. 197-219.
Pirela, A. (2007). Casas de Maracaibo 1674-1930. Maracaibo. Facultad de Arquitectura y Diseño. Universidad del Zulia.

Rodríguez, E., Machado, M., Quijano, E. (1994). La Otra Ciudad. Génesis de la ciudad petrolera de Maracaibo Facultad de Arquitectura. CONDES. Universidad del Zulia. Maracaibo, Venezuela. TAU. Producciones Editoriales, C.A. Venezuela.

Romero, P. (1997) La arquitectura del petroleo. Ediciones LAGOVEN, S, A. Filial de Petróleos de Venezuela S.A. PDVSA. Venezuela.

Romero, P. (2011). La geografia del poblamiento de la Venezuela petrolera. Capítulo 5. Tomo 1 La geografía histórica del poblamiento territorial venezolano. La tropicalidad venezolana. Primera parte: La geografía histórica del poblamiento territorial venezolano. GeoVenezuela Coleccion. Obtenido https://bibliofep.fundacionempresaspolar.org/media/1006/gv t1 c05 p286 329 Ires single preview.pdf

Quintanilla, M. Tecnología: un enfoque filosófico y otros ensayos de la filosofía de la tecnología. México, D.F.: Fondo de Cultura Económica, 2005. p. 27

Sanz, P. (2004). Las ciudades en la América hispana. Siglos XV al XVIII. Silex ediciones S.I. España.

Sempere M. (2000). Maracaibo, Ciudad y Arquitectura. Facultad de Arquitectura. CONDES. Universidad del Zulia. Ediciones Astro Data, C. A. Maracaibo, Venezuela.

Ripper, J., Vilas, N. (2007). Modelizandp la evolución urbana dela ciudad de Rio de Janeiro. Capítulo del libro. URBAMEDIA. Base de datos urbanos de áreas centrales, casos de ciudades argentinas y latinoamericanas. Facultad de Arquitectura, Diseño y Urbanismo. Universidad Nacional de Buenos Aires. (pp. 101-111). Argentina.

Ripper, J. Cury, R. (2007). El modelo de La Habana. Capítulo del libro. URBAMEDIA. Base de datos urbanos de áreas centrales, casos de ciudades argentinas y latinoamericanas. Facultad de Arquitectura, Diseño y Urbanismo. Universidad Nacional de Buenos Aires. (pp. 113-121). Argentina.

Stipech, A., Bredanini, G., Chiarella , M. (2007). Santa Fe Área Fundacional Representación VRML. Capitulo del libro. URBAMEDIA. Base de datos urbanos de áreas centrales, casos de ciudades argentinas y latinoamericanas. Facultad de Arquitectura, Diseño y Urbanismo. Universidad Nacional de Buenos Aires. (pp. 75-85). Argentina

Suarez, J. (2010). La Maracaibo suburbana 1897-1945. Origen y consolidación de los primeros suburbios. Tesis doctoral para optar al título de Doctor en Arquitectura. Doctorado en Arquitectura. Facultad de Arquitectura y Diseño. Univesridad del Zulia.

Terán, F. (2002). La forma de la ciudad hispanoamericana a través de sus representaciones. El urbanismo en el Nuevo Mundo. Ministerio de Educación y Cultura. Secretaria de Cultura. España.

Urdaneta, A., Parra, I., Cardozo, G. (2006). Los orígenes de Maracaibo y el dominio del Lago: diversidad social y mestizaje Procesos Históricos. Revista de Historia y Ciencias Sociales, 10, julio-diciembre, 2006, 94-144. Universidad de Los Andes, Mérida, (Venezuela) ISSN 1690-4818. 